\title{
Experimental Investigation of Drilling Parameters on Composite Materials
}

\author{
${ }^{1}$ Mr. P. N. E. Naveen, ${ }^{2}$ Mr. M. Yasaswi, ${ }^{3}$ Prof. R. V. Prasad \\ ${ }^{1,2,3}$ Department of Mechanical Engineering, GIET, Rajahmundry (A.P) INDIA
}

\begin{abstract}
Composite materials are light weight, remarkable strong and relatively inexpensive. Now these materials are being used for many automotive applications. It is difficult to machine hemp fiber composite materials with high efficiency to yield good quality products. Conventional drilling with twist drilling still remains one of the most economical and efficient machining process for Hole making as well as for riveting and fastening structural assemblies in the aerospace and automotive industries. The present work investigates the effects of the drilling parameters, speed and feed, on the damage factor in drilling composites glass, hemp \& sandwich fibers with different fiber volume fractions(i.e 10\%,20\%\&30\%). Three speeds, four feeds and three volume fractions are used in this study. The objective of this paper is to decrease the damage factor of composite materials with different fiber volume fractions, by varying drill parameters such as speed and feed. The composite material having the size of $100 \times 50 \times 3 \mathrm{~mm}$ and using the drill diameter as $6 \mathrm{~mm}$.
\end{abstract}

Keywords: damage factor, machinability, volume fractions of composites.

\section{Introduction}

Drilling is usually the final operation during the assembly of the structures in these applications. Any defect that leads to the rejection of the parts represents an expensive loss. For example in the aircraft industry, drilling associated damage factor accounts $60 \%$ of all part rejections during final assembly of an aircraft [1].more over the variation of volume fraction of the fibers makes the drilling process more complex, as proper feed, speed should be given particular volume fraction to produce a good hole. The quality of the drilled hole such as waviness/roughness of its wall surface, axial straightness and roundness of the hole cross-section can cause high stresses on the rivet, leading to its failure. Stress concentration, damage factor and micro cracking associated with machined holes significantly reduce the composites [2-4]. Several hole production processes, including conventional drilling, ultrasonic drilling, laser beam drilling, water jet drilling etc., have been proposed for a variety of economic and quality reasons. Conventional drilling is still the most widely used technique in industry today [6]. A major concern that has received considerable attention in drilling the holes in FRCM is damage factor, especially at bottom surface of the work piece (drill exit). The trust force developed during the drilling process affects the width of the damage factor zone. It is believed that there is a critical thrust force below which no damage occurs [4, 6-8].

Fiber reinforced plastics (FRP), are important structural materials. Numerous methods have been used, but conventional drilling still remains the un-avoidable process for making holes in composite laminates. Drilling induced damage is an area of prime concern. A number of theoretical and experimental endeavours have been made to study the influence of various parameters on drilling induced damage in FRP laminates. Different damage mechanisms have been conceptualised and methodologies to avoid damage or proposed. The present analysis on damage mechanism and to report initial experimental findings in drilling of glass, hemp \&sandwich fiber reinforced plastic composite laminates.

\section{NATURAL FIBERS: Source and classification}

Growing environmental awareness has triggered the researchers worldwide to develop and utilize materials that are compatible with the environment. In the process natural fibers have become suitable alternatives to traditional synthetic or manmade fibers and have the potential to be used in cheaper, more sustainable and more environmentally friendly composite materials. Natural organic fibers can be derived from either animal or plant sources. The majority of useful natural textile fibers are plant derived, with the exceptions of wool and silk. All plant fibers are composed of cellulose, whereas fibers of animal origin consist of proteins. Natural fibers in general can be classified based on their origin, and the plant-based fibers can be further categorized based on part of the plant they are recovered from. An overview of natural fibers is presented in Figure-1. Generally, plant or vegetable fibers are used to reinforce polymer matrices and a classification of vegetable fibers is given in Figure-2. Plant fibers are a renewable resource and have the ability to be recycled. The plant fibers leave little residue if they are burned for disposal, returning less carbon dioxide $\left(\mathrm{CO}_{2}\right)$ to the atmosphere than is removed during the plant's growth. However, when the specific modulus of natural fibers (modulus per unit specific gravity) is considered, the natural fibers show values that are comparable to or even 
better than glass fibers. Material cost savings, due to the use of natural fibers and high fiber filling levels, coupled with the advantage of being non-abrasive to the mixing and moulding equipment make natural fibers an exciting prospect. These benefits mean natural fibers could be used in many applications, including building, automotive, household appliances, and other applications.

Table-2.1 properties of glass and natural fibers

\begin{tabular}{|l|l|l|l|}
\hline properties & Glass & hemp & sandwich \\
\hline Density $(\mathrm{g} / \mathrm{cm} 3)$ & 2.55 & 1.48 & 1.78 \\
\hline Modulus $(\mathrm{GPa})$ & 73 & 70 & 60 \\
\hline Tensile strength $(\mathrm{MPa})$ & 2400 & $550-900$ & $480-700$ \\
\hline Elongation to failure $(\%)$ & 3 & 1.6 & 2.1 \\
\hline
\end{tabular}

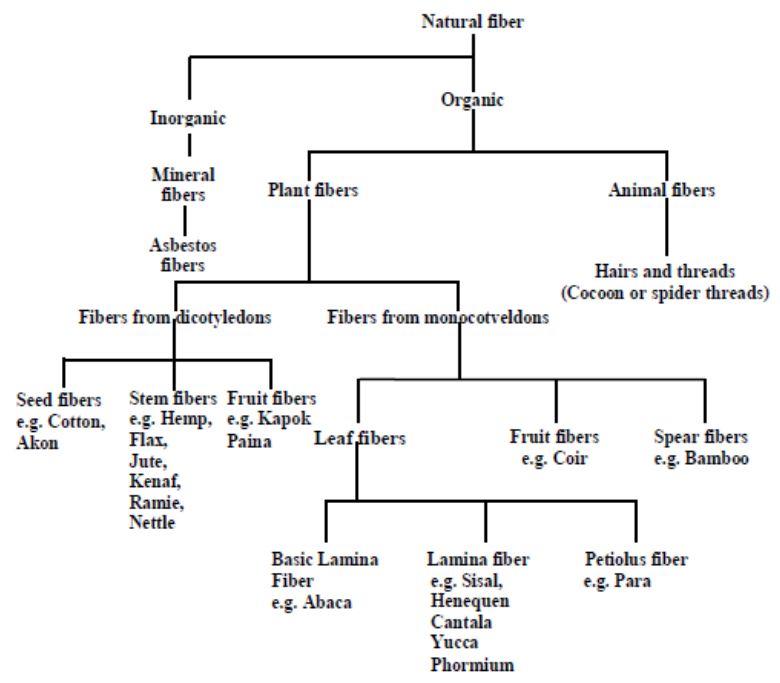

Figure-1 Overview of natural fibers

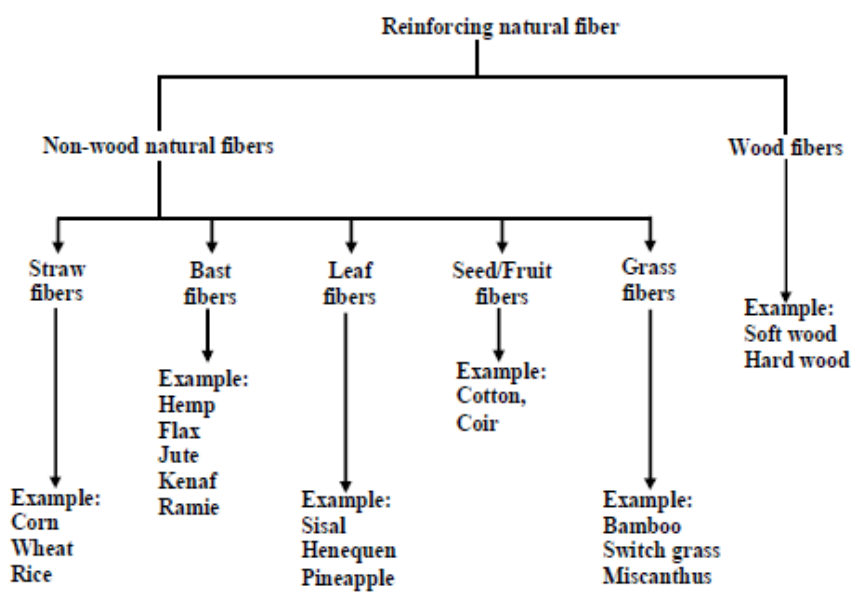

Figure-2 Classification of natural fiber that can be used as reinforcements in polymers

\section{Related Work}

Lachaud,et al [9] stated that using a twist dril causes several types of defects in the laminates, which can be divided inn to four main types. Hole entry defect, through it does not appear on every occasion, is related to the fibrous characters of the material and the drill geometry. It leads to the tearing of the first ply of the first layer in contact with the drill. Circular defect is linked to the presence of angle created by the direction of the fibers of the ply concerned and by the direction of the cutting edge. Depending upon the angular position of the cutting edges and just before being cut, the fibers are subjected to an alternating action of bending or compression stresses. The unilateral behaviour of carbon fibres leads to an elliptical hole shape. Damage from a heat source is due to the friction between the fibers and two minor cutting edges of the drill. It can cause to 
damage to the matrix at the hole edge, thus increasing the likelihood of torn fibers due to the mechanical action of the minor cutting edges. Removal of fibers leads to the roughness defect on the sidewall of the hole.

Damage factor at the exit hole is caused by the cutting conditions in which the chisel edge of the twist drill cannot cut through the material. The trust force of the drill may cause normal stress i.e. likely to open the ply interface. Damage factor between plies spread beyond the hole diameter, and can occur at varying depths as the drill progress. Damage factor occurs mainly because of the localised bending in the zone situated at the point of attack of the drill.

A number of researches came up with other forms of damage. Mathew et al [10] identified matrix burning, damage factor, debonding, fiber pull-out as the major sources of damage. Di paola et al [11] stated three distinguishable mechanisms for damage, namely plate bulge, crack opening, and fiber tearing or twisting. Ho-cheng and Dharan [7] found that damage takes place both at the entrance and the exit and thus differentiated the damage as peel-up at entrance and push-out at the exit and illustrates a few forms of drilling induced damage.

Effect of tool geometry on cutting forces has been analysed by chen [7], miller[13] in his exclusive study on drill bit configurations concluded that eight-faced drill point gave best result for graphite-epoxy laminates. Greater number of holes to failure was encountered while drilling with carbide drills as reported by ramulu et al [14]. A number of experimental forays for operating conditions optimization [7], [14] and [15] have been made but a global function still elude the composite industry.

\section{Experimental Procedure And Tool Materials}

Drilling of natural fiber reinforced polymer laminates depend on the cutting speeds (S) and feed rate (f) along with other parameters. In the present study these are recognized as the prime factors that influence the drilling induced damage. Four-layered unidirectional glass, hemp and sandwich fiber composite laminates were made. Hand layup technique with controlled pressure was adopted to make these laminates. Curing was done at room temperature for $24 \mathrm{~h}$. The matrix was G.P resin with hardener catalyst and cobalt as the accelerator. The specimens were cut to size of $100 \mathrm{~mm} \times 50 \mathrm{~mm} \times 3 \mathrm{~mm}$

The experiments were carried out at three different levels of cutting speeds and four feed rates. We used carbide drills because of better surface finish and more number of holes to failure, a $6 \mathrm{~mm}$ standard solid carbide twist drill was used to drill the holes in FRP laminates. The cutting speed was varied, namely $40 \mathrm{~m} / \mathrm{min}$, $60 \mathrm{~m} / \mathrm{min}, \& 80 \mathrm{~m} / \mathrm{min}$ and the feed rates as $0.1 \mathrm{~mm} / \mathrm{min}, 0.2 \mathrm{~mm} / \mathrm{min}, 0.3 \mathrm{~mm} / \mathrm{min}, \& 0.5 \mathrm{~mm} / \mathrm{min}$. The drilled holes were observed using dye penetrate test. The laminates were cleaned using acetone. The coloured dye was then sprayed on the region around the hole. The spraying action was carried out at different angles to make certain that the dye penetrates every section of the damaged area. The area around the hole was later observed under the ultra violet light. The fluorescent dye gave a clear idea of damage zone around the drilled hole.

\subsection{TWIST DRILL}

The most common type of drill is a standard-point twist drill. This type of drill is versatile and can be used on a variety of materials such as wood, plastic, masonry, ceramic and metal. The drill bits have two spiral grooves running the length of the drill. These grooves aid in transporting cutting fluids to the drill tip and in removing the chips from the hole. These types of drill bits are held in chucks or collets on machines that are either hand-held or automated. This type of drilling can often cause burrs at both the entrance and exit of the hole and parts will often need a subsequent deburring operation to smooth out the holes.

\subsection{DAMAGE FACTOR}

The damage factor occurring at the side of the hole entrance was calculated accordingly. In the determination of damage factor (DF), the conventional method of division of damage diameter to drill diameter which was used by Davim and his colleagues [17] was preferred. In the application of this method, a circle is made passing through the minimum points at which the damaged sides around the hole spread intensively and the maximum damage diameter $(\mathrm{Dm})$ is specified. As seen in Fig 2 the biggest values X1 and X2 of damaged sides on the same line passing through the centre are obtained and $\mathrm{Dm}$ is determined by the Formula $\mathrm{Dm}=\mathrm{X} 1+$ $\mathrm{X} 2+\mathrm{D}$.

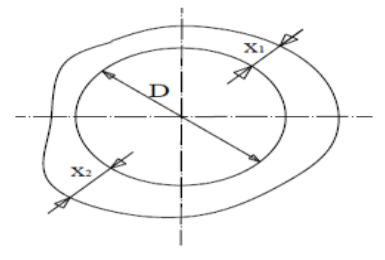

$$
\begin{aligned}
& \mathrm{D}_{\mathrm{m}}=\text { Maximum damage diameter } \\
& \mathrm{D}=\text { Drill diameter } \\
& \mathrm{x}_{1}, \mathrm{x}_{2}=\text { Damage width } \\
& \mathrm{D}_{\mathrm{m}}=\mathrm{D}+\mathrm{x}_{1}+\mathrm{x}_{2} \\
& \mathrm{HF}=\text { Damage factor } \\
& \mathrm{HF}=\mathrm{D}_{\mathrm{m}} / \mathrm{D}
\end{aligned}
$$

Figure 3. Determination of minimum damage diameter. 


\section{Experimental Investigation Of Drilling Parameters On Composite Materials}

The maximum damage diameter was determined from the digital pictures and then the damage factor was calculated by dividing the maximum damage diameter (Dm) to drill diameter (D). In Fig 4 the determination of damage diameter is shown.

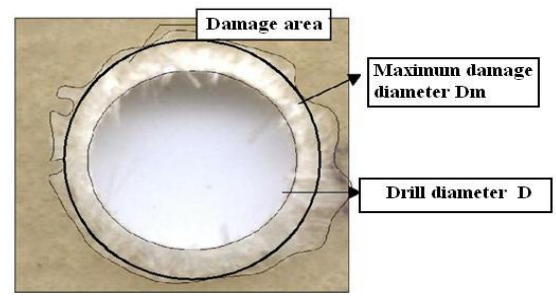

Figure. 4. Scheme of Delamination factor determines.

\section{Result And Discussion}

It is clear from fig 4 there exist a damage zone around the drilled hole in HFRP laminates. It is seen that the damage zone is dependent on the fibre orientation. This is in strong exception to results reported by lachaud et al[1]. Maximum damage is observed by drilling at high feed rate eighth high cutting speed. Uncut fibres and damage factors are the predominant damage forms observed. In this present investigation the efforts have been put to quantify the damage zone around the hole. A methodology is under development that makes use of the digital image processing technique to quantify the areas of the damage zone. After measuring the max dia in the damage zone the damage factor is calculated by the following equation

\section{$\mathbf{F d}=$ max dia/actual dia}

Table $3,5 \& 7$ shows the results of the damage factor, for the two sets of the drilling tests, as a function of the cutting parameters .In figure 3 we observe the evaluation of the damage factor with the feed for different cutting speed values. However, as the feed rate is increased irrespective of the volume fraction the damage factor deteriorated. Similar trends were observed for increased feeds. A volume fraction of $30 \%, 40 \mathrm{~m} / \mathrm{min}$ speed and lower feed rates were found to give optimum results.

Table 2. Maximum dia of hemp fiber based composites

\begin{tabular}{|c|c|c|c|c|c|c|c|c|c|c|c|}
\hline \multirow[b]{2}{*}{ RUN } & \multirow[b]{2}{*}{ SPEED } & \multirow{2}{*}{$\begin{array}{l}\text { FEED } \\
\text { RATE }\end{array}$} & \multicolumn{3}{|c|}{$10 \%$} & \multicolumn{3}{|c|}{$20 \%$} & \multicolumn{3}{|c|}{$30 \%$} \\
\hline & & & 1 & 2 & AVG & 1 & 2 & AVG & 1 & 2 & AVG \\
\hline 1 & \multirow{4}{*}{40} & .1 & 6.008 & 6.04 & 6.024 & 6.036 & 6.06 & 6.048 & 6.008 & 6.1 & 6.054 \\
\hline 2 & & .2 & 6.09 & 6.006 & 6.048 & 6.07 & 6.074 & 6.072 & 6.166 & 6.05 & 6.108 \\
\hline 3 & & .3 & 6.1 & 6.14 & 6.12 & 6.228 & 6.06 & 6.144 & 6.236 & 6.1 & 6.168 \\
\hline 4 & & .5 & 6.228 & 6.12 & 6.174 & 6.164 & 6.22 & 6.192 & 6.256 & 6.2 & 6.228 \\
\hline 5 & & .1 & 6.032 & 6.004 & 6.018 & 6.03 & 6.03 & 6.03 & 6.032 & 6.04 & 6.036 \\
\hline 6 & & .2 & 6.04 & 6.02 & 6.03 & 6.1 & 6.02 & 6.06 & 6.07 & 6.074 & 6.072 \\
\hline 7 & & .3 & 6.116 & 6.1 & 6.108 & 6.2 & 6.04 & 6.12 & 6.164 & 6.1 & 6.132 \\
\hline 8 & & .5 & 6.10 & 6.188 & 6.144 & 6.24 & 6.12 & 6.18 & 6.204 & 6.18 & 6.192 \\
\hline 9 & \multirow{4}{*}{80} & .1 & 6.002 & 6.01 & 6.006 & 6.004 & 6.02 & 6.012 & 6.012 & 6.012 & 6.012 \\
\hline 10 & & .2 & 6.02 & 6.04 & 6.03 & 6.084 & 6.012 & 6.048 & 6.04 & 6.8 & 6.06 \\
\hline 11 & & .3 & 6.13 & 6.05 & 6.09 & 6.166 & 6.05 & 6.108 & 6.06 & 6.18 & 6.12 \\
\hline 12 & & .5 & 6.2 & 6.052 & 6.126 & 6.236 & 6.1 & 6.168 & 6.228 & 6.12 & 6.174 \\
\hline
\end{tabular}

Table 3. Damage factor of hemp fiber based composite materials with different volume fractions

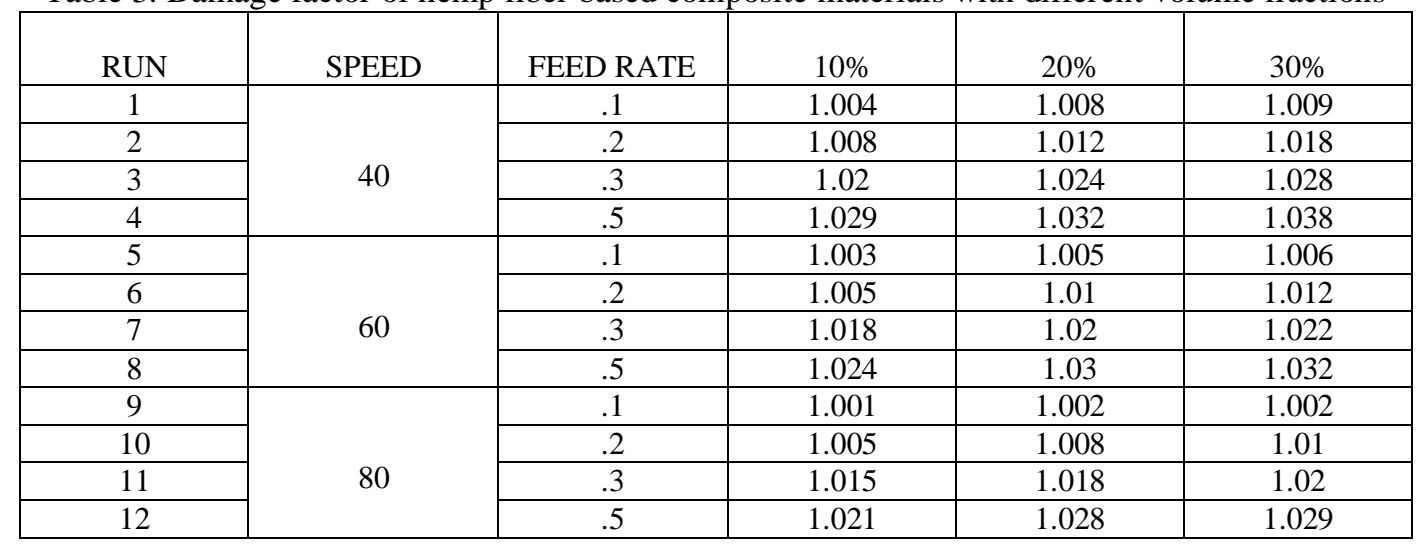


Experimental Investigation Of Drilling Parameters On Composite Materials

Table 4. Maximum dia of sandwich fiber based composites materials with different volume fractions

\begin{tabular}{|c|c|c|c|c|c|c|c|c|c|c|c|}
\hline \multirow[b]{2}{*}{ RUN } & \multirow[b]{2}{*}{ SPEED } & \multirow{2}{*}{$\begin{array}{l}\text { FEED } \\
\text { RATE }\end{array}$} & \multicolumn{3}{|c|}{$10 \%$} & \multicolumn{3}{|c|}{$20 \%$} & \multicolumn{3}{|c|}{$30 \%$} \\
\hline & & & 1 & 2 & AVG & 1 & 2 & $\mathrm{AVG}$ & 1 & 2 & AVG \\
\hline 1 & \multirow{4}{*}{40} & .1 & 6.008 & 6.04 & 6.024 & 6.024 & 6.06 & 6.042 & 6.08 & 6.016 & 6.048 \\
\hline 2 & & .2 & 6.03 & 6.03 & 6.03 & 6.064 & 6.08 & 6.072 & 6.05 & 6.15 & 6.102 \\
\hline 3 & & .3 & 6.016 & 6.08 & 6.048 & 6.152 & 6.1 & 6.126 & 6.19 & 6.206 & 6.198 \\
\hline 4 & & .5 & 6.12 & 6.3 & 6.21 & 6.256 & 6.2 & 6.228 & 6.22 & 6.26 & 6.24 \\
\hline 5 & \multirow{4}{*}{60} & .1 & 6.006 & 6.03 & 6.018 & 6.05 & 6.01 & 6.03 & 6.02 & 6.064 & 6.042 \\
\hline 6 & & .2 & 6.008 & 6.04 & 6.024 & 6.08 & 6.064 & 6.72 & 6.17 & 6.01 & 6.09 \\
\hline 7 & & .3 & 6.09 & 6.03 & 6.06 & 6.2 & 6.04 & 6.12 & 6.12 & 6.02 & 6.07 \\
\hline 8 & & .5 & 6.236 & 6.1 & 6.168 & 6.2 & 6.10 & 6.15 & 6.1 & 6.26 & 6.18 \\
\hline 9 & \multirow{4}{*}{80} & .1 & 6.004 & 6.02 & 6.012 & 6.026 & 6.01 & 6.018 & 6.02 & 6.016 & 6.018 \\
\hline 10 & & .2 & 6.016 & 6.02 & 6.018 & 6.024 & 6.06 & 6.042 & 6.04 & 6.08 & 6.06 \\
\hline 11 & & .3 & 6.056 & 6.04 & 6.048 & 6.1 & 6.08 & 6.09 & 6.06 & 6.15 & 6.108 \\
\hline 12 & & .5 & 6.16 & 6.14 & 6.15 & 6.076 & 6.23 & 6.138 & 6.2 & 6.148 & 6.174 \\
\hline
\end{tabular}

Table 5. Damage factor of sandwich fiber based composites materials with different volume fractions

\begin{tabular}{|c|c|c|c|c|c|}
\hline RUN & SPEED & FEED RATE & $10 \%$ & $20 \%$ & $30 \%$ \\
\hline 1 & \multirow{4}{*}{40} & .1 & 1.004 & 1.007 & 1.008 \\
\hline 2 & & .2 & 1.005 & 1.012 & 1.017 \\
\hline 3 & & .3 & 1.008 & 1.021 & 1.033 \\
\hline 4 & & .5 & 1.035 & 1.038 & 1.04 \\
\hline 5 & \multirow{4}{*}{60} & .1 & 1.003 & 1.005 & 1.007 \\
\hline 6 & & .2 & 1.004 & 1.012 & 1.015 \\
\hline 7 & & .3 & 1.01 & 1.02 & 1.025 \\
\hline 8 & & .5 & 1.028 & 1.025 & 1.03 \\
\hline 9 & \multirow{4}{*}{80} & .1 & 1.002 & 1.003 & 1.003 \\
\hline 10 & & .2 & 1.003 & 1.007 & 1.01 \\
\hline 11 & & .3 & 1.008 & 1.015 & 1.018 \\
\hline 12 & & .5 & 1.025 & 1.023 & 1.029 \\
\hline
\end{tabular}

Table 6. Maximum dia of glass fiber based composites materials with different volume fractions

\begin{tabular}{|c|c|c|c|c|c|c|c|c|c|c|c|}
\hline \multirow{2}{*}{ RUN } & \multirow{2}{*}{ SPEED } & \multirow{2}{*}{$\begin{array}{l}\text { FEED } \\
\text { RATE }\end{array}$} & \multicolumn{3}{|c|}{$10 \%$} & \multicolumn{3}{|c|}{$20 \%$} & \multicolumn{3}{|c|}{$30 \%$} \\
\hline & & & 1 & 2 & AVG & 1 & 2 & AVG & 1 & 2 & AVG \\
\hline 1 & \multirow{4}{*}{40} & .1 & 6.03 & 6.12 & 6.075 & 6.0 & 6.06 & 6.03 & 6.02 & 6.12 & 6.05 \\
\hline 2 & & .2 & 6.05 & 6.09 & 6.07 & 6.0 & 6.04 & 6.02 & 6.0 & 6.07 & 6.035 \\
\hline 3 & & .3 & 6.05 & 6.12 & 6.085 & 6.0 & 6.06 & 6.03 & 6.02 & 6.02 & 6.02 \\
\hline 4 & & .5 & 6.06 & 6.06 & 6.06 & 6.0 & 6.22 & 6.11 & 6.07 & 6.08 & 6.075 \\
\hline 5 & \multirow{4}{*}{60} & .1 & 6.04 & 6.04 & 6.04 & 6.06 & 6.03 & 6.04 & 6.0 & 6.04 & 6.02 \\
\hline 6 & & .2 & 6.07 & 6.05 & 6.06 & 6.01 & 6.01 & 6.01 & 6.02 & 6.04 & 6.03 \\
\hline 7 & & .3 & 6.30 & 6.02 & 6.16 & 6.02 & 6.04 & 6.03 & 6.02 & 6.08 & 6.05 \\
\hline 8 & & .5 & 6.10 & 6.07 & 6.085 & 6.0 & 6.12 & 6.06 & 6.0 & 6.03 & 6.015 \\
\hline 9 & \multirow{4}{*}{80} & .1 & 6.15 & 6.01 & 6.08 & 6.15 & 6.08 & 6.115 & 6.0 & 6.03 & 6.015 \\
\hline 10 & & .2 & 6.12 & 6.09 & 6.10 & 6.30 & 6.12 & 6.21 & 6.04 & 6.02 & 6.03 \\
\hline 11 & & .3 & 6.02 & 6.02 & 6.02 & 6.07 & 6.05 & 6.06 & 6.04 & 6.08 & 6.06 \\
\hline 12 & & .5 & 6.27 & 6.04 & 6.155 & 6.0 & 6.07 & 6.035 & 6.01 & 6.05 & 6.03 \\
\hline
\end{tabular}

Table 7. Damage factor of glass fiber based composites materials with different volume fractions

\begin{tabular}{|c|c|c|c|c|c|}
\hline RUN & SPEED & FEED RATE & $10 \%$ & $20 \%$ & $30 \%$ \\
\hline \multirow{4}{*}{4} & .1 & 1.0125 & 1.005 & 1.008 \\
\cline { 4 - 6 } & \multirow{4}{*}{40} & .2 & 1.011 & 1.003 & 1.0058 \\
\cline { 4 - 6 } & & .3 & 1.014 & 1.005 & 1.003 \\
\cline { 3 - 6 } & & .5 & 1.01 & 1.018 & 1.0125 \\
\hline 3 & .1 & 1.006 & 1.006 & 1.003 \\
\hline 5 & & & &
\end{tabular}


Experimental Investigation Of Drilling Parameters On Composite Materials

\begin{tabular}{|c|c|c|c|c|c|}
\hline 6 & \multirow{3}{*}{60} & .2 & 1.01 & $\bar{~} 1.0016$ & 1.005 \\
\hline 7 & & .3 & 1.026 & 1.005 & 1.0083 \\
\hline 8 & & .5 & 1.014 & 1.01 & 1.0025 \\
\hline 9 & \multirow{4}{*}{80} & .1 & 1.013 & 1.019 & 1.0025 \\
\hline 10 & & .2 & 1.016 & 1.035 & 1.005 \\
\hline 11 & & .3 & 1.003 & 1.01 & 1.01 \\
\hline 12 & & .5 & 1.025 & 1.0058 & 1.005 \\
\hline
\end{tabular}
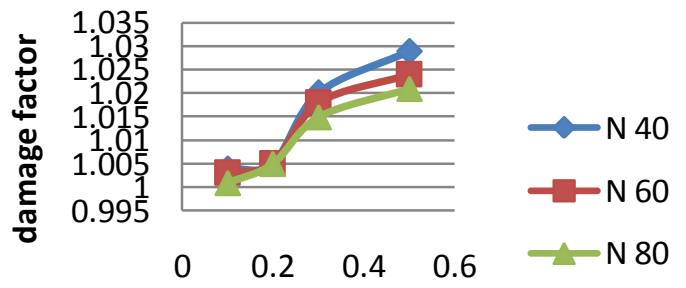

feed rate $(\mathrm{mm} / \mathrm{rev})$

Fig 5: Effect of hemp fiber based vol fraction $10 \%$ On the damage factor for speeds of 40, 60, $80 \mathrm{rev} / \mathrm{min}$

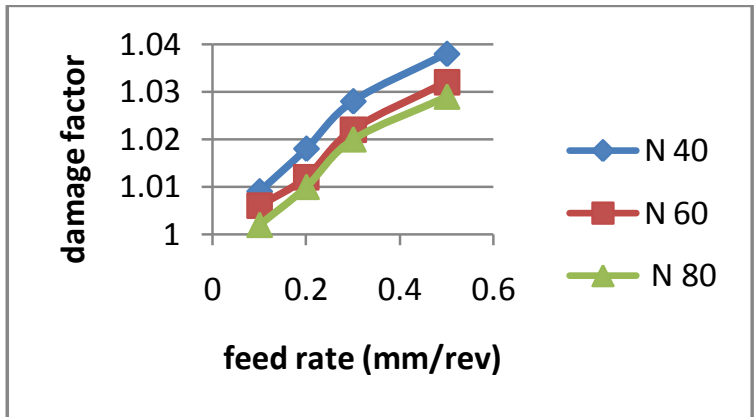

Fig7: Effect of hemp fiber based vol fraction $30 \%$ On the damage factor for speeds of 40, 60, $80 \mathrm{rev} / \mathrm{min}$

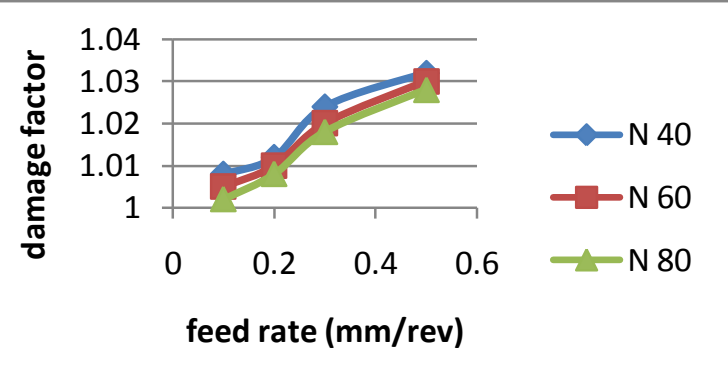

Fig 6: Effect of hemp fiber based vol fraction $20 \%$ on the damage factor for speeds of $40,60,80 \mathrm{rev} / \mathrm{min}$

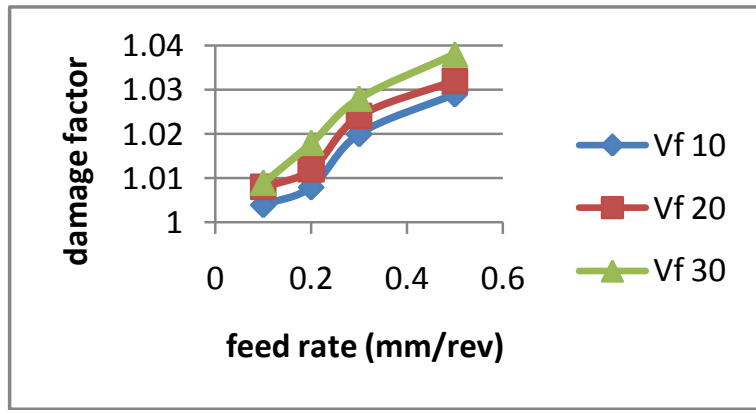

Fig 8: Effect of cutting speed (N 40) on the damage factor for hemp fiber vol fractions of $10,20 \& 30 \%$

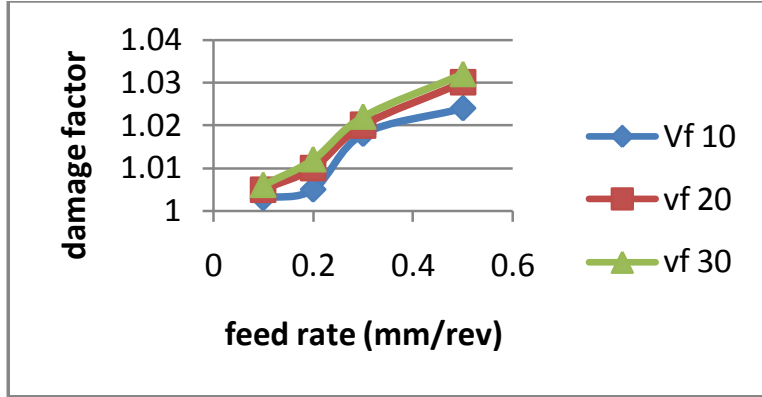

Fig 9: Effect of cutting speed (N 60) on the damage Factor for hemp fiber vol fractions of $10,20 \& 30 \%$

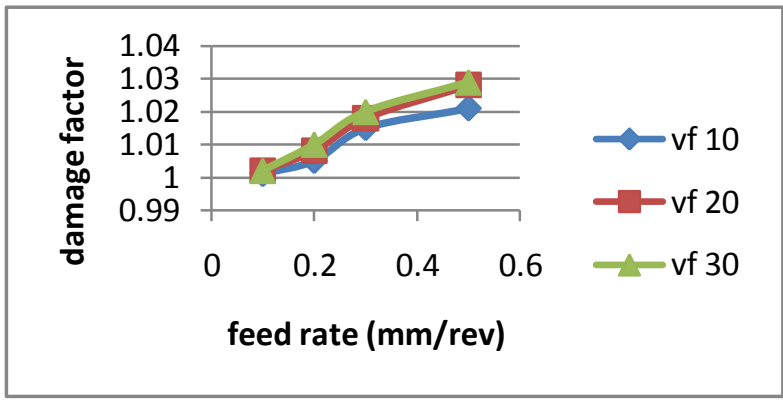

Fig10: Effect of cutting speed (N 80) on the damage factor for hemp fiber vol fractions of $10,20 \& 30 \%$
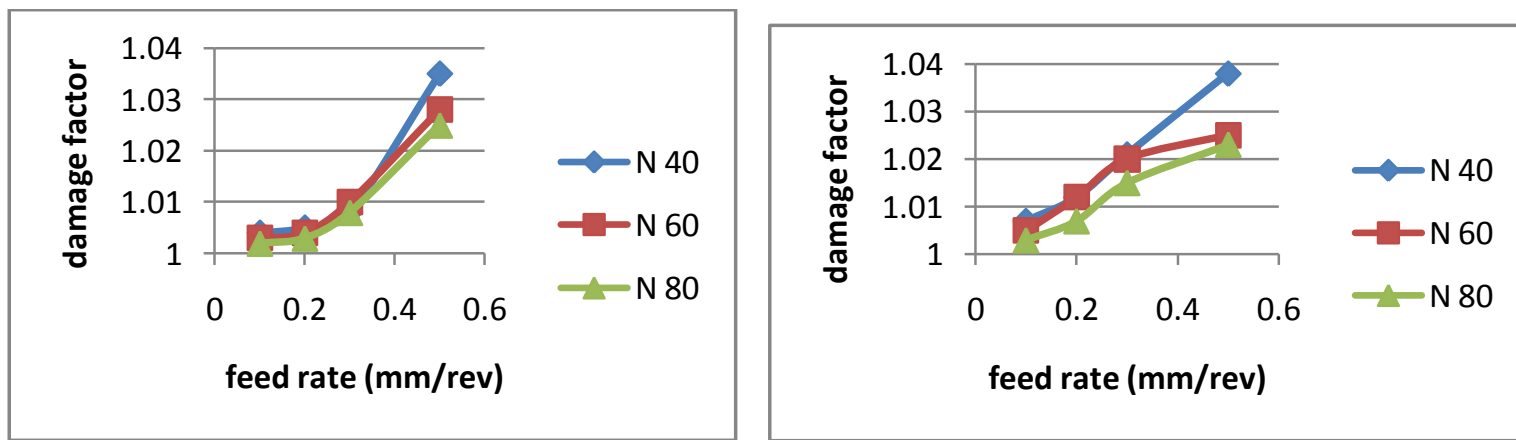

Fig 11: Effect of sandwich fiber based vol fraction 10\% Fig 12: Effect of sandwich fiber based vol fraction $20 \%$ On the damage factor for speeds of 40,60, $80 \mathrm{rev} / \mathrm{min}$ on the damage factor for speeds of 40,60, $80 \mathrm{rev} / \mathrm{min}$ 

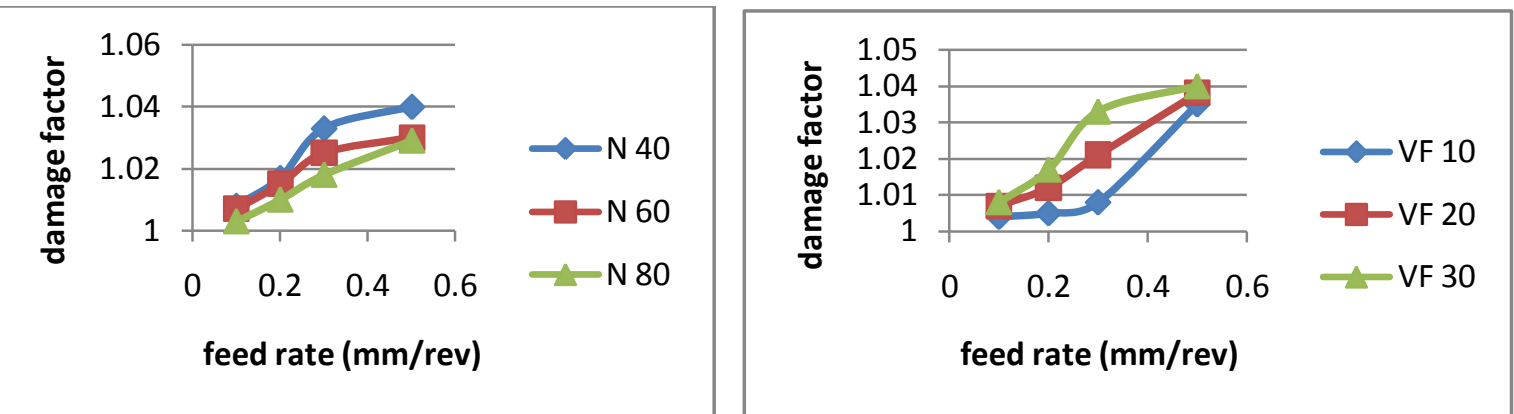

Fig 13: Effect of sandwich fiber based vol fraction 30\% Fig 14: Effect of cutting speed (N 40) on the damage On the damage factor for speeds of 40,60, $80 \mathrm{rev} / \mathrm{min}$ factor for sandwich fiber vol fractions of $10,20 \& 30 \%$

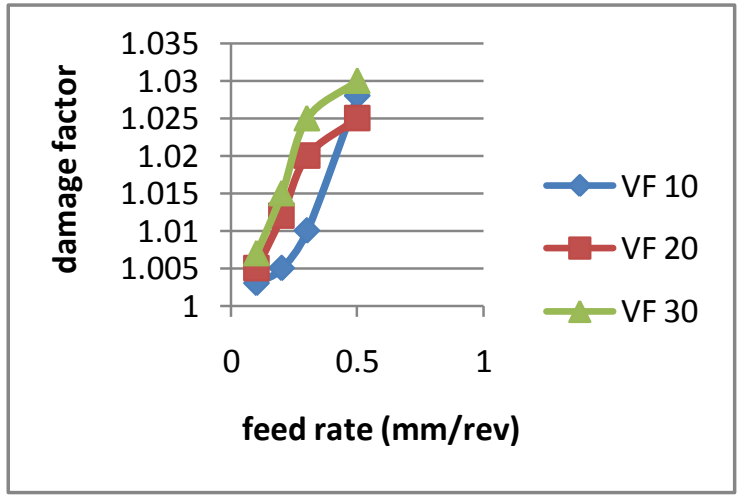

Fig 15: Effect of cutting speed (N 60) on the damage Factor for sandwich fiber vol fractions of $10,20 \& 30 \%$

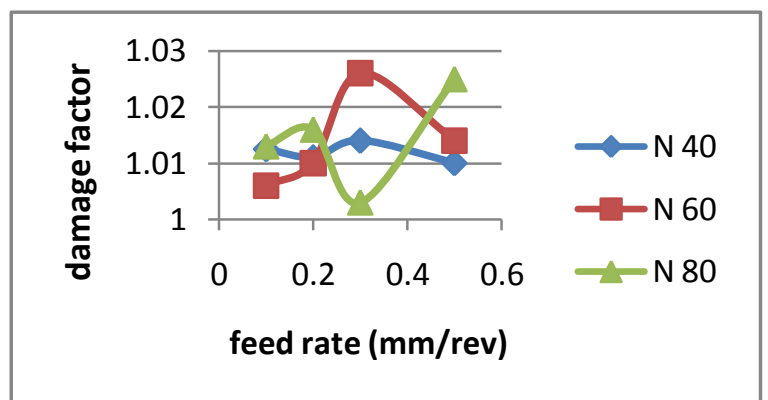

Fig 17: Effect of glass fiber based vol fraction $10 \%$ On the damage factor for speeds of 40, 60, $80 \mathrm{rev} / \mathrm{min}$

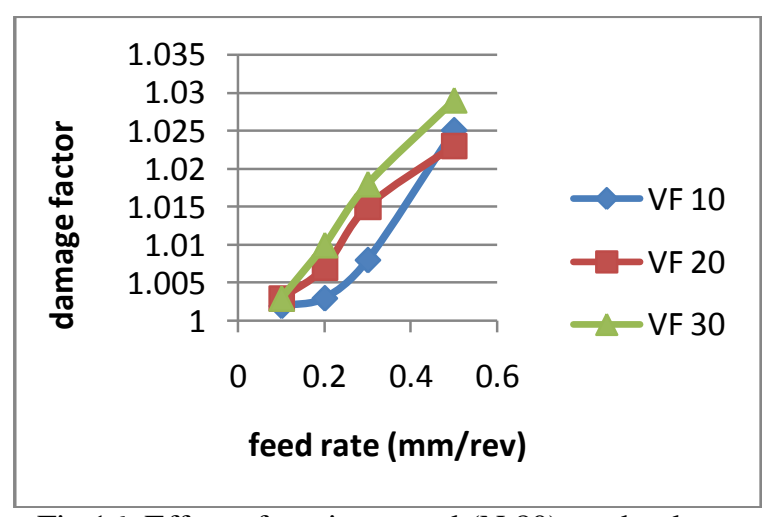

Fig 16: Effect of cutting speed (N 80) on the damage $\%$ factor for sandwich fiber vol fractions of $10,20 \& 30 \%$

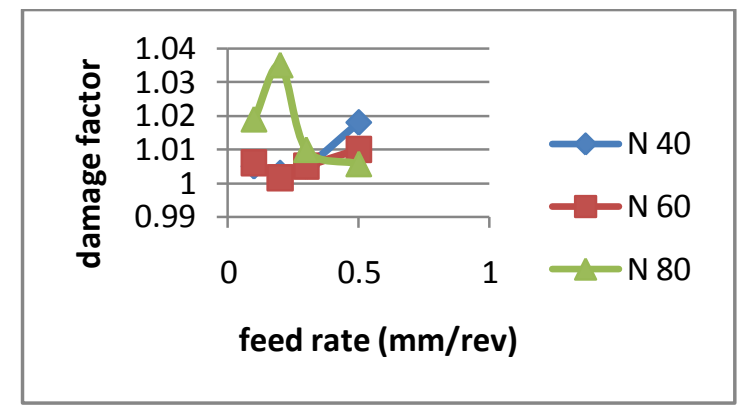

Fig 18: Effect of glass fiber based vol fraction $20 \%$ on the damage factor for speeds of $40,60,80 \mathrm{rev} / \mathrm{min}$

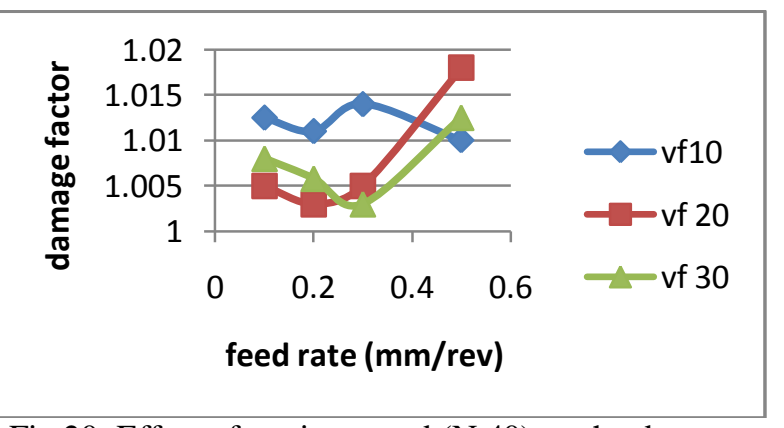

Fig 20: Effect of cutting speed (N 40) on the damage

factor for glass fiber vol fractions of $10,20 \& 30 \%$
Fig 19: Effect of glass fiber based vol fraction $30 \%$

On the damage factor for speeds of 40, 60, $80 \mathrm{rev} / \mathrm{min}$

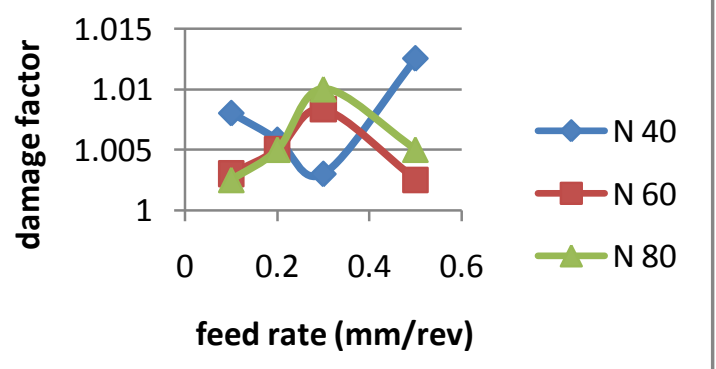




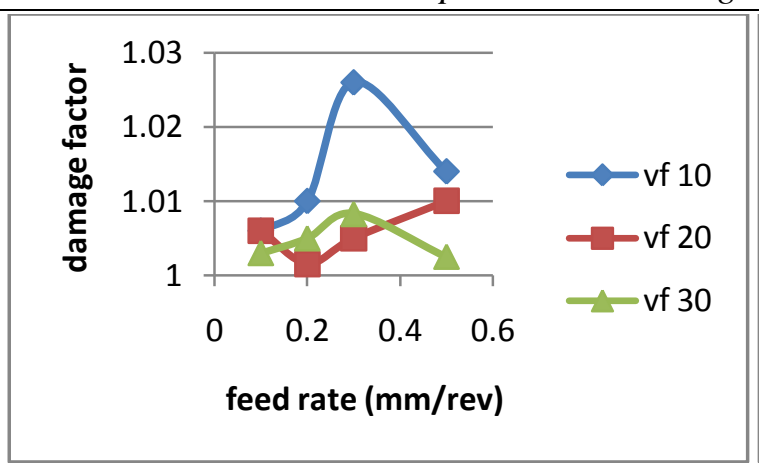

Fig 21: Effect of cutting speed (N 60) on the damage Factor for glass fiber vol fractions of $10,20 \& 30 \%$

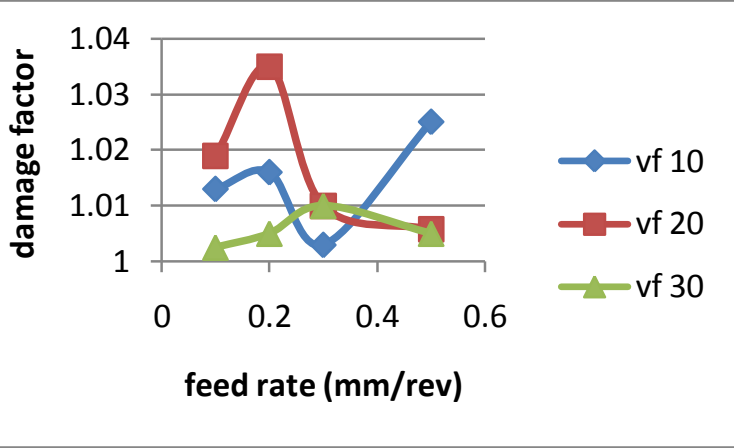

Fig 22: Effect of cutting speed (N 80) on the damage factor for glass fiber vol fractions of $10,20 \& 30 \%$

\section{Conclusions}

Cutting speeds and the feed rate are the two important factors included in this investigation. The damage is observed using the digital photography. It is found that the damage around the hole is predominant at higher feed rates. The effect of drilling parameters is seen that, their exist a cutting speed range for which the damage zone is minimized. Damage zone observed around a hole shows a partial elliptical shape, the major axis being along the direction of the fibres. At higher feed, fibres are not cut cleanly and some uncut fibres are observed. The efforts are now on to quantify the damage zone around the hole and to develop a global damage criterion for FRP composite materials.

It is observed from this experiment high cutting speeds $(40,60,80 \mathrm{rev} / \mathrm{min})$ and lower feed rates $(0.1,0.2$ $\mathrm{mm} / \mathrm{rev}$ ) are best suited for drilling FRP composite laminates. Therefore it is important to make a trade of between the higher feed rate resulting in damage factor and the low feed rate resulting in thermal damage. From this result we can conclude that the FRP composites are used for many structural and non- structural applications.

\section{References}

[1]. T.L.Wong, S.M.Wu, G.M.Croy, An analysis of delamination in drilling composite materials, in proceedings of $14^{\text {th }}$ SAMPE Technology conference, Atlanta, GA, USA 1982, pp 471-483.

[2]. Park KY, Choi JH, Lee DG. Delaminatiopn free and high efficiency drilling of carbon fiber reinforced plastics. J Compos Mater 1995:29(15):1988-2002

[3]. Andrews SD Ochoa OO, Owens SD. The effect of fastner hole defects . J Compos Mater 1993:27(1):3-20

[4]. Tagliaferri V, Caprino G, Diterlizzi A. effect of drilling pareameters on the finish and mechanical properties of GFRP composites. J Mach Tools manufacturing 1990:30(1):77-84

[5]. Chandrasekharan V ,Kapoor SG,Devor RE. a mechanistic approach to predicting the cutting force in drilling with applications to fiber reinforced composite materials. J Eng Ind, ASME 1995, 117:559-70.

[6]. Jain S, Yang DCH. Delamination free drilling of composite laminates. ASME 1995, 116:475-81,398-405.

[7]. Ho-Cheng H, Dharan CKH. Delamination during drilling in composite laminates J Eng Ind, ASME 1990, 112:236-9

[8]. Tsao CC,Hocheng H. computerised photography and c scan for measuring delamination in the drilling of composite materials using various drills. J Mach Tools manufacturing 2005:45:1282-7.

[9]. F Lachaud R Piquet, F Collombet and L Surien. Drilling of composite structures. Composite structures , volume 52,2001,pp 511516.

[10]. J Mathew, N Ramakrishnan and N K Naik.trepanning on uni directional composites. Composites , part A Vol 30,1999,pp 951-959

[11]. G DiPaolo, S G Kapoor and R E DeVor. An experimental investigation of the crack growth phenomenon for the drilling of FRP materials. Transactions of ASME,journal of engineering for industry,vol 118,1996

[12]. Wen-Chou Chen.. some experimental investigations in the drilling of carbon fiber reinforced plastic laminates. International journal of Mach tools manufacture. 1997 pp 1097-1108

[13]. J A Miller. Drilling graphite/epoxy at Lockheed. American machinist and automated manufacturing 1987,pp 70-79

[14]. M Ramulu,T Branson and D Kim. A study of drilling composites and titanium stacks , composite structures, volume 54,2001,pp 6777

[15]. Shih-Chieh Lin and Jung-Ming Shen. Drilling uni directional glass fiber reinforced composite materials at high speed. Journal of composite materials,33/9,1999,pp 827-851

[16]. J.P. Davim, P. Reis, C.C. Antonio, Experimental study of drilling glass fibre reinforced plastics (GFRP) manufactured by hand layup, Composites Science and Technology 64 (2004) 289-297 . 